\section{TINJAUAN PENGARUH SISTEM AKUNTANSI PENGGAJIAN DAN PENGUPAHAN DALAM MENDUKUNG PENGENDALIAN INTERN GAJI DAN UPAH PADA HOTEL SALAK THE HERITAGE}

\author{
Harry Roestiono, Tarida Marlin dan Siti Nurfithriyani \\ Program Studi Akuntansi, Sekolah Tinggi Ilmu Ekonomi Kesatuan \\ Bogor, Indonesia \\ Email : lemlit@stiekesatuan.ac.id
}

payroll, payment, internal controll, accounting

system.

014

Submitted: JANUARI 2016

Accepted: FEBRUARI 2016

\begin{abstract}
The roles of internal control and accounting information system owned by a firm cannot be separated with each other in company's operating in order to run smoothly and in accordance with the standardised procedures. And so with payroll and payment operating, it takes a proper system to run its activities. Thus, the company will be able to avoid possible risks during transactions. This research is aimed at investigating how the application of payroll system and to determine if the existing system helps the management in controlling its payroll and payment system. This is a descriptive research using primary data such as interviews with management and secondary data. Data are collected using observation technique, interviews and library research. The result concludes that the company has run a proper system in its payroll and thus helped the management to control its payroll and payment system
\end{abstract}

Key words: payroll, payment, internal controll, accounting system.

\title{
PENDAHULUAN
}

Bagi perusahaan gaji dan upah merupakan biaya yang cukup besar jumlahnya dan salah satu unsur yang memiliki banyak resiko kemungkinan terjadinya manipulasi dan pemborosan, untuk itu manajemen perusahaan harus terus memberikan perhatian terhadap pengendalian internnya, dalam hal ini yaitu pengendalian intern gaji dan upah.

Pengendalian intern merupakan kebijakan dan prosedur yang melindungi kekayaan perusahaan dari penyalahgunaan, mengecek ketelitian dan keandalan akuntansi, dan memastikan bahwa peraturan yang berlaku dipatuhi sebagaimana mestinya. Sesuai dengan salah satu syarat pengendalian intern yang baik adalah bahwa tidak ada satu individu pun yang diperbolehkan memegang kekuasaan sepenuhnya dan bertanggung jawab penuh dalam melaksanakan semua fase kegiatan dari awal hingga selesai. Jika diperlukan adanya pemisahan tugas yang jelas untuk masing-masing kegiatan yaitu antara pelaksanaan, pembukuan, dan pembuatan laporan mengenai hasil-hasilnya, salah satunya adalah kegiatan yang berhubungan dengan prosedur penentuan besarnya gaji dan upah serta pembayarannya. Untuk dapat menciptakan pengendalian intern tidak terlepas dari sistem akuntansi yang diterapkan oleh perusahaan.

Sistem akuntansi merupakan serangkaian dari formulir-formulir, catatancatatan, laporan-laporan, serta alat-alat lainnya yang dikoordinasikan sehingga memberikan informasi yang diperlukan pimpinan perusahaan dalam pengambilan keputusan. Terlepas dari itu semua harus disadari bahwa penyelewengan dan pemborosan bukan berarti sistem pengendalian intern itu lemah, tetapi merupakan pertanda bahwa terdapat kekurangan dalam pengendalian intern tersebut, yang harus

\section{JIAKES}

Jurnal Ilmiah Akuntansi Kesatuan Vol. 4 No. 1,2016 pg. $014-020$ ISSN 2337-7852 
payroll,

payment,

internal controll,

accounting

system

015 diselidiki adalah apakah penyebabnya. Apabila struktur pengendalian intern sudah diterapkan dengan baik, tetapi diantara staff atau pegawai, mengadakan kolusi untuk melakukan kecurangan maka pengendalian intern itu akan sia-sia.

Sistem akuntansi yang baik memperlihatkan prosedur urutan kegiatan sehingga secara otomatis pengawasan telah berjalan. Bila ada kejanggalan dalam kegiatan operasi perusahaan akan mudah ditelusuri kembali sehingga dapat segera diketahui timbulnya masalah, dan manajemen perusahaan dapat segera mengambil keputusan serta langkah-langkah apa yang akan dilakukan guna mengatasi masalah tersebut. Dengan demikian terjadi hubungan yang erat antara sistem akuntansi dengan pengendalian intern dalam perusahaan termasuk pengendalian intern penggajian dan pengupahan. HotelSalak ini banyak mempekerjakan tenaga kerja dengan berbagai tingkatan.

\section{MAKSUD DAN TUJUAN}

1. Untuk mengetahui bagaimana penerapan system akuntansi penggajian dan pengupahan pada Hotel Salak The Heritage.

2. Untuk mengetahui bagaimana Penerapan Pengendalian Intern Gaji dan Upah Pada Hotel Salak The Heritage.

3. Untuk mengetahui apakah system akuntansi penggajian dan pengupahan yang diterapkan oleh perusahaan dapat membantu manajemen dalam pengendalian intern Gaji dan Upah pada Hotel Salak The Heritage.

\section{TINJAUAN PUSTAKA}

Ada beberapa teori yang mendukung Penelitian ini diantaranya yaitu :

Pengendalian Intern (internal control) menurut Ikatan Akuntan Indonesia (IAI) adalah Sebagai suatu proses yang dijalankan oleh dewan komisaris, manajemen dan persolnel lain entitas yang didisain untuk memberikan keyakinan memadai tentang pencapaian 3 golongan tujuan berikut ini: 1). keandalan pelaporan keuangan. 2). efektifitas dan efisiensi operasi. 3). kepatuhan terhadap hukum dan peraturan yang berlaku.

Mulyadi (2008:121) dalam buku Sistem Informasi Akuntansi tentang Gaji dan Upah mengemukakan bahwa Gaji umumnya merupakan pembayaran atas penyerahan jasa yang dilakukan oleh karyawan yang mempunyai jenjang jabatan manajer, sedangkan upah umumnya merupakan pembayaran atas penyeraha jasa yang dilakukan oleh karyawan pelaksana (buruh). Umumnya gaji dibayarkan secara tetap perbulan, sedangkan upah dibayarkan berdasarkan hari kerja, jam kerja atau jumlah satuan produk yang di hasilkan.

Baridwan (2005:3) menyatakan sistem akuntansi gaji dan upah adalah "Suatu kerangka dari prosedur yang saling berhubungan sesuai dengan skema yang menyeluruh untuk melaksanakan kegiatan dan fungsi utama perusahaan".

\section{METODE PENELITIAN}

Metode yang digunakan dalam penelitian ini adalah Deskriptif Kualitatif. Yaitu metode yang bertujuan untuk mengetahui hubungan antara dua variabel atau lebih dalam suatu perusahaan. Setelah semua data yang diperoleh dari hasil penelitian dikumpulkan, dipelajari kemudian dianalisa untuk mengetahui apakah faktor-faktor telah memadai guna pengujian hipotesis. 
Adapun tujuan dari system pengendalian intern adalah untuk memberikan jaminan ketelitian dan ketepatan terhadap perhitungan dan pembayaran serta pencatatan gaji. Selain itu system pengendalian intern bertujuan untuk memberikan keyakinan bahwa gaji yang diberikan tepat kepada orang yang berhak menerimanya. Agar informasi itu dapat berguna bagi manajemen dalam pengambilan keputusan perlu diterapkan adanya pengendalian intern yang berhubungan dengan unsur-unsur pengendalian intern.

\section{Lingkungan Pengendalian}

Lingkungan pengendalian memegang peranan yang sangat penting dalam pengendalian intern yang sudah disusun oleh perusahaan. Lingkungan pengendalian yang baik menandakan manajemen memiliki kepentingan akan pengendalian intern maka seluruh anggota organisasi akan bertindak teliti dalam menjalankan tugas dan tanggung jawabnya sesuai dengan kebijakan-kebijakan yang telah ditetapkan oleh perusahaan.

Struktur organisasi yang baik jika dikaitkan dengan pengendalian adalah yang dapat menggambarkan secara tegas garis wewenang dan tanggung jawab setiap bagian dalam organisasi. Dimana tanggung jawab fungsional dalam organisasi didasarkan pada prinsip-prinsip berikut yaitu harus dipisahkan fungsi-fungsi operasi dan penyimpanan dari fungsi akuntansi serta suatu fungsi tidak boleh diberi tanggung jawab penuh untuk melaksanakan semua tahap suatu transaksi.

Dari bentuk organisasi seperti ini diperoleh berbagai keuntungan. Antara lain dengan adanya kesatuan perintah, bawahan hanya menerima perintah dari orang yang menjadi atasannya secara langsung berarti dia mempertanggung jawabkan tugastugasnya kepada atasannya tersebut. Hubungan antara atasan dan bawahan dalam struktur garis ini akan menyebabkan disiplin yang tinggi dan pengendalian terhadap karyawan mudah dilakukan. Garis wewenang dan tanggung jawab yang jelas dapat memudahkan pengambilan tindakan terhadap kecurangan yang terjadi dan dapat ditelusuri unit mana yang bertanggung jawab terhadap kecurangan-kecuragan tersebut.

\section{Penilaian Resiko}

Penilaian risiko merupakan komponen kedua dalam pengendalian intern pada perusahaan. Perusahaan yang baik tentunya sudah memperkirakan risiko-risiko yang mungkin akan terjadi dalam kegiatan operasional perusahaan. Dalam penilaian resiko Hotel Salak The Heritage melakukan beberapa upaya agar tidak terjadinya penyimpangan pengeluaran kas dalam proses penggajian, dilakukan dengan cara setiap pengeluaran kas penggajian yang dilakukan harus memiliki bukti yang sah dan mendapatkan otorisasi dari yang berwenang dan menggunakan system-sistem yang mendukung penggajian dan pengupahan sehingga risiko yang dapat timbul pada system penggajian dan pengupahan pada Hotel Salak The Heritage seperti risiko penipuan, risiko pemalsuan data, risiko penyalahgunaan ID Card dan risiko kecurangan yang mungkin terjadi setiap waktu.

Untuk memperkecil risiko yang kemungkinan terjadi Hotel Salak The Heritage telah melakukan seleksi yang sangat ketat dalam perekrutan karyawan dari mulai psikotes dan wawancara dengan mengajukan beberapa syarat yang harus ditaati oleh karyawan Hotel Salak The Heritage maka hotel menerapkan pelatihan untuk setiap karyawan baru.

\section{Aktivitas Pengendalian}

Aktivitas pengendalian merupakan bagian ketiga dalam pengendalian intern perusahaan. Dengan adanya pengendalian ini perusahaan dapat menentukan 
payroll,

payment,

internal controll,

accounting

system

017

kebijakan dan prosedur serta dapat memastikan bahwa petunjuk dan arahan yang diberikan oleh manajemen puncak dilaksanakan dengan baik oleh para karyawan.

Struktur organisasi Hotel Salak The Heritage telah dengan jelas menjelaskan tugas dan tanggung jawab karyawan terutama dalam kegiatan penggajian dan pengupahan dimana ada petugas yang bertugas untuk mengawasi dan memonitoring kas keluar.

Pengendalian fisik terhadap harta dan catatan serta dokumen disimpan serta diarsipkan secara rapi pada lemari besi dan sebagian asset berharga seperti suratsurat penting dititipkan pada Bank.

Pengecekan secara independen terhadap kinerja karyawan Hotel Salak The Heritage dilakukan dengan pemisahan fungsi otorisasi pengeluaran kas. Adanya internal auditor yang memadai memudahkan Hotel Salak The Heritage dalam melaksanakan kegiatan operasionalnya agar sesuai dengan standar operasional prosedur (SOP) yang sudah ditetapkan. Setiap pengeluaran kas untuk penggajian selalu diotorisasi oleh pejabat yang berwenang agar dapat dilakukan pengecekan bahwa pemberian gaji dan upah telah sesuai dengan prosedur yang ada.

Semua kegiatan pengendalian dalam kegiatan operasional Hotel Salak The Heritage seluruhnya telah menggunakan teknologi yang komputerisasi dalam pengolahan datanya sehingga penomoran dokumen dan catatan yang terjadi dalam setiap transaksi dilakukan secara langsung dan tidak ada penomoran ganda karena telah digunakan suatu software yang dapat menolak data masuk jika ada nomor yang sama.

Pada Hotel Salak The Heritage dalam proses penggajian terdapat 2 orang yang dilibatkan yaitu HRD dan Accounting. HRD bertugas untuk menghitung gaji karyawan sampai dengan pembayaran gaji dan accounting bertugas untuk memeriksa kembali kebenaran dan ketelitian daftar gaji sebelum dilakukan pembayaran gaji Hotel Salak The Heritage juga melibatkan pihak luar yaitu Bank karena pembayaran gaji yang dilakukan untuk karyawan tetap dilakukan dengan mentransfer ke nomor rekening masing - masing karyawan nya sehingga akan terdapat bukti pembayaran yang sah berupa bukti transfer dari bank.

Dokumen dan catatan yang memadai dapat membantu dalam pencatatan data yang akurat sehingga apabila ada penambahan jumlah gaji dapat dilakukan dengan benar. Dokumen - dokumen yang digunakan dalam sistem penggajian pada Hotel Salak The Heritage antara lain dokumen pendukung perubahan gaji, kartu jam hadir, rekap jam kerja, daftar gaji karyawan, slip gaji, bukti transfer pembayaran gaji.

Pada Hotel Salak The Heritage setiap tahunnya secara rutin melakukan penilaian terhadap kinerja karyawan bagi karyawan yang di anggap memiliki kinerja baik akan diberikan penghargaan serta dipromosikan kenaikan jabatan dan kenaikan gaji.

\section{Informasi dan Komunikasi}

Hotel Salak The Heritage telah menggunakan sistem informasi yang efektif dengan adanya sistem Payroll Data Base suatu sistem aplikasi penggajian yang digunakan oleh Hotel Salak The Heritage untuk pengolahan dan upah. Dengan adanya sistem tersebut dapat membantu accounting atau pihak yang terlibat dalam penggajian untuk meminimalisir kecurangan serta memepercepat perhitungan gaji secara komputerisasi dan komunikasi yang terjalin dapat berjalan dengan baik untuk pihak-pihak yang berkepentingan seperti atasan dan bawahan yang akhirnya dapat memberikan keyakinan yang memadai bahwa transaksi telah dicatat, telah diotorisasi dan telah dinilai dengan wajar.

\section{Pemantauan (Monitoring)}

Pemantauan berhubungan dengan penilaian mutu suatu pengendalian intern secara berkelanjutan. Hotel Salak The Heritage sendiri memiliki divisi audit internal 
dalam hal pemantauan untuk memastikan semua pengendalian telah berjalan dengan baik dan sesuai dengan prosedur yang ditetapkan.

Dari hasil penelitian penulis dan setelah dibandingkan dengan landasan teori yang terdapat di bab sebelumya maka unsur pengendalian intern pada perusahaan ini telah cukup memadai, dimana hal ini dapat dijelaskan sebagai berikut:

1. Struktur organisasi

Dalam struktur organisasi Hotel Salak The Heritage terlihat bahwa adanya pembagian yang jelas antar tiap bagian. Hal ini akan menyebabkan disiplin yang tinggi karena harus melaporkan hasil tugasnya tepat waktu kepada atasannya. Dengan demikian maka pengendalian terhadap karyawan mudah dilakukan. Pelaksanaan tanggung jawab setiap bagian secara umum telah berjalan dengan baik. Dimana fungsi pencatatan waktu hadir yang dilakukan oleh bagian pegawai. Bagian keuangan terpisah dari fungsi pembuat daftar gaji dan upah.

2. Pegawai yang cukup

Perusahaan telah menempatkan karyawan sesuai dengan tingkat pendidikan, serta pengalaman kerja mereka. Dengan kata lain bahwa perusahaan memperkerjakan karyawan sesuai dengan kemampuan mereka, sehingga mereka bisa mempertanggungjawabkan pekerjaannya. Dalam hal ini karyawan yang diterima adalah yang mutuya sesuai dengan tanggung jawabnya serta jujur dalam bekerja. Untuk memperoleh karyawan seperti ini maka perusahaan menerapkan prosedur penerimaan karyawan ditetapkan oleh pusat. Setiap penerimaan, penempatan, mutasi maupun pemberhentian karyawan dibuatkan surat keputusan yang ditandatangani oleh Direktur Utama dan Kepala Bagian Sumber Daya Manusia. Selain itu, ada pula surat perjanjian kerja antara karyawan dengan perusahaan.

3. Sistem wewenang dan prosedur pencatatan

Dari segi pemisahan tugas, maka setiap kegiatan dalam persiapan, perhitungan serta pendistribusian gaji dan upah harus mendapat persetujuan yang berwenang, yang berguna untuk menghindari adanya transaksi yang menyimpang dari semestinya. Misalnya dalam pembayaran gaji dan upah harus diotorisasi oleh fungsi keuangan dan mendapat persetujuan dari fungsi akuntansi kemudian dibayarkan kepada karyawan yang bersangkutan. Setiap potongan atas gaji dan upah karyawan selain dari pajak penghasilan karyawan didasarkan atas surat potongan gaji dan upah yang diotorisasi oleh bagian sumber daya manusia. Setiap karyawan yang namanya tercantum dalam daftar gaji dan upah harus memiliki surat pengangkatan karyawan yang ditandatangani oleh Direktur Utama. Bukti kas keluar untuk pembayaran gaji dan upah diotorisasi oleh fungsi akuntansi. Daftar hadir diotorisasi oleh bagian sumber daya manusia sebagai fungsi pencatatan waktu. Daftar gaji dan upah diotorisasi oleh fungsi sumber daya manusia. Perubahan yang terjadi dalam catatan penghasilan karyawan direkonsiliasi dengan daftar gaji dan upah karyawan. Tarif upah dalam kartu jam kerja diverifikasi ketelitiannya oleh fungsi akuntansi.

4. Praktik-praktik yang sehat

Perusahaan telah menjalankan praktik-praktik yang sehat. Bagian sumber daya manusia sebagai fungsi pembuat daftar gaji dan upah,menyimpan catatan penghasilan karyawan. Bagian akuntansi memverifikasi kebenaran payroll,

payment, internal controll, accounting system

\section{8}


payroll,

payment, internal controll, accounting system

\section{9}

dan ketelitian perhitungan pembuatan daftar gaji dan upah sebelum dilakukan pembayaran. Pengisian absensi dan kartu jam hadir diawasi oleh orang yang berwenang.

Hal terakhir adalah kebijakan dan prosedur kepegawaian Hotel Salak The Heritage telah membuat kebijakan-kebijakan yang bermanfaat bagi kelangsungan hidup perusahaan dan kesejahteraan para karyawannya. Tentunya ini mendorong pengendalian intern yang efektif. Salah satu kebijakan yang ditetapkan perusahaan adalah kebijakan mengenai pengupahan. Antara lain bahwa upah minimum yang diberikan pada karyawan sesuai dengan Upah Minimum Regional (UMR). Disamping itu karyawan juga mendapat tunjangan kesehatan, dimana apabila karyawan sakit maka seluruh biaya perobatan ditangung oleh perusahaan.

\section{SIMPULAN}

1. Sistem akuntansi penggajian dan pengupahan pada Hotel Salak The Heritage sudah baik karena adanya dokumen -dokumen serta catatan akuntansi yang memadai seperti daftar gaji, daftar hadir, rekening koran bank, jurnal dan buku besar. Keseluruhan dokumen tersebut sudah terprogram dalam komputer, sehingga dapat meminimalkan kesalahan dalam pembayaran gaji dan upah.

2. Penerapan Pengendalian Intern Gaji dan Upah Pada Hotel Salak The Heritage dilihat dari Sistem wewenang dan prosedur penggajian dan pengupahan pada perusahaan ini sudah baik. Dapat dilihat dari setiap transaksi yang berhubungan dengan gaji dan upah harus mendapat otorisasi dari bagian yang berwenang. Contoh : daftar gaji dan upah harus diotorisasi oleh bagian keuangan dan Pembayaran gaji dilakukan dengan cara mentransfer ke rekening masing-masing karyawan. Dalam hal ini pembayaran gaji dan upah lebih efektif dan efisien.

3. Untuk mengetahui apakah system akuntansi penggajian dan pengupahan yang diterapkan oleh perusahaan dapat membantu manajemen dalam pengendalian intern Gaji dan Upah pada Hotel Salak The Heritage sudah cukupmemadai dapat dilihat dari pengawasan terhadap kehadiran karyawan dilakukan dengan time card dan diawasi dengan ketat sehingga tidak terjadi kecurangan serta kebijakankebijakan dan prosedur-perosedur kepegawaian yang diterapkan oleh perusahaan sangat mendukung terhadap pengendalian intern gaji dan upah. Salah satunya adalah bahwa setiap karyawan diangkat dan diberhentikan dan dipindah tugaskan melalui surat keputusan. Prosedur yang ada dalam perusahaan ini terdiri dari prosedur penerimaan karyawan dan perusahaan prosedur pemutusan hubungan kerja dan lain sebagainya. Dan setiap prosedur tersebut dilaksanakan oleh pihak yang berwenang.

\section{DAFTAR PUSTAKA}

B Romney Marshall, Paul John Steinbar. 2006. System Informasi Akuntansi. Edisi 9, Jilid 1. Rineka Cipta, Jakarta.

B Romney Marshall, Deny Armos Kwary and Dewi Fitrisiah. 2006. Sistem Informasi Akuntansi Akuntansi (Accounting Information System), Jilid 2. Salemba Empat, Jakarta.

Baridwan, Zaki. 2003. Sistem Informasi Akuntansi. Sekolah Tinggi Ilmu Ekonomi YKPN. 
Baridwan, Zaki. 2005. Sistem Akuntansi Penyusunan Prosedur dan Metode. Yogyakarta: BPFE

C. Van Home, James dan M.Wachowicz, Jr. 2003. Financial Management, Edisi 12, Penerbitan Salemba 4, Jakarta.

Dasaratha V. Rama dan Frederick L. Jones. 2008. Sistem Informasi Akuntansi, Salemba Empat, Jakarta.

Febriansyah, Reza. 2007. Sistem Informasi Akuntansi Piutang Terhadap Biaya Operasional Pada Anak Perusahaan PT. Astra International. Program Studi Akuntansi STIE KESATUAN Bogor.

Fitriansyah, Dradjat. 2009. Sistem Pengendalian Intern Penggajian pada PT. Suryaraya Lestari 2 Kabupaten Mamuju Sulawesi Barat. Fakultas Ekonomi Universitas Pembangunan Nasional "VETERAN".

H Bonar George., William S Hopwood. 2003. Accounting Information System, Edisi 8, Pearson Custom Publishing.

H Bonar George., William S Hopwood. 2003. Sistem Informasi Akuntansi. Jilid 8, PT. Indeks, Komplek Gramedia.

Hansen/Women, 2009. Managerial Accounting. Edisi 8. Penerbitan Salemba Empat, Jakarta.

James A Hall. 2007. Accounting Information System. Edisi 13, Salemba Empat, Jakarta.

Mauliza, Febria. 2009. Peranan Sistem Akuntansi Dalam Mendukung Pengendalian Intern Gaji dan Upah Pada PT. Mopoli Raya. Program Studi Akuntansi Universitas Sumatera.

Mulyadi, 2003. Sistem Perencanaaan dan Pengendalian Manajemen. Salemba Empat, Jakarta.

Mulyadi, 2005. Sistem Perencanaaan dan Pengendalian Manajemen. Edisi 3. Salemba Empat, Jakarta.

Mulyadi, 2006. Ekonomi Sumber Daya Manusia: Dalam Perspektif Pembangunan, Jilid 1. PT. Raja Grafindo Persada.

Mulyadi, 2008. Jurnal Ekonomi dan Bisnis Indonesia. Vol (12). Masalah 1. Universitas Gajah Mada.

Tandean, 2009. Evaluasi Sistem Penggajian Karyawan Dalam Kaitannya Dengan Efektivitas Pelaksanaan Pengendalian Intern Pengeluaran Kas Pada PT. Pondok Pinang Motor.

http://sanoesi.wordpress.com

www.omegaakuntansi.com

http://andinanissa2.blogspot.com

http://wartawarga.gunadarma.ac.id

http://anastasias01.blogspot.com

http://hendreatno.blog.itttelkom.ac.id payroll,

payment, internal controll, accounting system

\section{0}

